\title{
Behavior of Italian Lemon Rootstocks towards Mal Secco Leaf Infection with Tunisian Fungus Phoma tracheiphila in Controlled Environment
}

\author{
Sana Ziadi ${ }^{1 *}$, Samir Chebil ${ }^{1}$, Angela Ligorio ${ }^{2}$, Antonio Ippolito ${ }^{2}$ and Ahmed Mliki ${ }^{1}$ \\ ${ }^{1}$ Laboratory of Plants Molecular Physiology, Centre of Biotechnology Borj-Cedria, BP 901 Hammam-Lif, 2050, Tunisia \\ ${ }^{2}$ Department of Agro Forestry and Environmental Biology and Chemistry, University of Bari, Via G Amendola 165/A, Bari 70126, Italy
}

\begin{abstract}
Studying behaviors of four Italian lemon rootstocks towards Mal Secco leaf infection with the fungus Phoma tracheiphila, isolated in Tunisia in controlled environment, is the aim of this research work. It involves prospection of infected lemons fields in Tunisia, isolation and morphological identification of the fungus, preparation of inoculum and infection of leaves of four rootstocks. Following the artificial inoculation in three assessments after 10, 20 and 30 days post inoculation (dpi) by observing the appearance of disease symptoms, counting the percentage of positive inoculation and determining the average disease intensity according to the leaf empirical scale. All these parameters indicated about the behaviour of the rootstock towards disease in addition to allowing the classification of the four lemon rootstocks according to susceptibility to Mal Secco. Therefore Volkameriana which showed great sensitive behavior was considered as susceptible rootstock. However, Sour Orange showed an intermediate susceptibility to Mal Secco infection and was classified as tolerant rootstock. Nevertheless Flying Dragon and Citrange Troyer were considered as resistant rootstocks after showing a great resistance to the leaf infection by Phoma tracheiphila.
\end{abstract}

Keywords: Lemon; Mal secco; Phoma tracheiphila; Artificial inoculation; Controlled environment

\section{Introduction}

Phoma tracheiphila (Petri) Kantsch et Gik. is a mitosporic fungus causing a destructive vascular disease of citrus named 'mal secco'. The disease present in almost all the Mediterranean countries [1] has been reported in Tunisia for the first time in 1960 in northern regions; then, the disease spread in major producing areas becoming endemic [2]. In infected lemon trees first symptoms appear on younger leaves, with vein discoloration and chlorosis; then they become yellow and fall. A progressive basipetal desiccation of shoots, branches, and trunk follows and, finally, the whole plant may die. The infected xylem of young shoots as well as of main and secondary branches and trunk show a yellow or pink-salmon to reddish discoloration $[3,1]$. The principal host species is lemon (Citrus limon L.), but the fungus has also been reported on many other Citrus spp. such as cedar (C. medica L.), lime (C. aurantifolia Christ.), bergamot (C. bergamia Risso), chinotto (C. myrtifolia Raf.), sour orange (C. aurantium L.), rough lemon (C. jambiri Lush) and Volkamerian lemon (C. volkameriana Ten. et Pasq.). The erratic field behavior of the disease, makes its damages difficult to estimate [1].

All these damages cause a real risk to citriculture in Tunisia and also in Mediterranean countries by limiting the growth and the development and by threatening directly and indirectly the production of many citrus varieties. It was discussed that complete control of the disease would double the lemon production in lemon-producing countries [4]. In some cases, infections have affected up to $100 \%$ of the plants of susceptible lemon cultivars [5]. Preventive measures, phytosanitary programs, and early diagnosis are the most effective ways to limit the introduction and further spread of the pathogen [6]. In Italy, many studies have been carried out to obtain tolerant scion and rootstocks to 'mal secco' and a few promising cultivars were obtained [7]. Different techniques have been developed to ascertain host susceptibility/resistance of citrus to mal secco disease. An early testing was developed by [8] in which mature leaves are inoculated [9].

The objective of this work was to study the behavior of four Italian lemon rootstocks towards Mal Secco leaf infection, caused by the fungus $P$. tracheiphila isolated in Tunisia, in controlled environment.

\section{Materials and Methods}

\section{Prospection and sampling}

Several prospections were done from autumn 2010 to spring 2011 in different citrus regions of Tunisia such as Mornag and the Cap Bon, the latter being which represents the main productive area. Twigs and fruits were collected from different varieties of citrus in various Tunisian locations. Five samples per tree were taken from all infected trees in the orchard showing Mal Secco symptoms. The plant material was reserved in plastic bags on ice until processing in the laboratory then was conserved at $4^{\circ} \mathrm{C}$. The isolate Phoma tracheiphila used in this study was isolated from infected twigs of Citrus bergamia from infected Tunisian citrus field by Mal Secco located in El Gobba which is situated in region of Cap Bon in Tunisia.

\section{Fungal isolation}

Infected twigs were immersed in a sodium hypochlorite solution $100 \%$ for $30 \mathrm{~s}$ then immediately rinsed with distilled water for five min. After sterilization of infected plant material, twigs were cut into small pieces. The sterilized samples were placed on Potato Dextrose Agar Petri dishes. The plates were kept at $25^{\circ} \mathrm{C}$ and fungal growth was monitored daily.

*Corresponding author: Sana Ziadi, Laboratory of Plants Molecular Physiology, Centre of Biotechnology Borj-Cedria, BP 901 Hammam-Lif, 2050, Tunisia, Fax: +216 79412638; E-mail: ziadi.sana@yahoo.fr

Received October 21, 2012; Accepted November 27, 2012; Published December 01, 2012

Citation: Ziadi S, Chebil S, Ligorio A, Ippolito A, Mliki A (2012) Behavior of Italian Lemon Rootstocks towards Mal Secco Leaf Infection with Tunisian Fungus Phoma tracheiphila in Controlled Environment. J Plant Pathol Microb 3:150. doi:10.4172/2157-7471.1000150

Copyright: (c) 2012 Ziadi S, et al. This is an open-access article distributed under the terms of the Creative Commons Attribution License, which permits unrestricted use, distribution, and reproduction in any medium, provided the original author and source are credited. 


\section{Morphological identification}

P. tracheiphila was identified visually, after 14 days of incubation, on the basis of detection of specific phenotypic characteristics and microscopic fungal structures such as characteristic pigmentation and typical phialoconidia. Examination under microscope showed phialoconidia characteristics of this fungus.

\section{Preparation of inoculums}

The inoculum was obtained according to Salerno and Catara's technique slightly modified [10]. In particular, $250 \mathrm{ml}$ fluted shake flasks containing $120 \mathrm{ml}$ carrot broth and small pieces of mycelium, taken from the edge of actively growing colony of the isolate, were put in a rotary shaker adjusted to $180 \mathrm{rpm}$. After four days of growth an abundant production of phialoconidia was obtained at a temperature of about $25^{\circ} \mathrm{C}$ and in the dark. The inoculum was filtrated with sterilized filter paper, centrifuged at $7000 \mathrm{rpm}$ at a temperature of $20^{\circ} \mathrm{C}$ for 15 min. The supernatant was eliminated and the pellet was recovered. Two $\mathrm{ml}$ of sterile distilled water was added to the pellet and the mixture was vortexed. By using an hemacytometer phialoconidia were counted and their concentration adjusted to $1 \times 107$ conidia/ml. This concentration resulted the best one for leaf inoculation as reported by [8].

\section{Procedure of leaf inoculation}

Plants were put in a green house, at a temperature of about $20^{\circ} \mathrm{C}$ and irrigated every $48 \mathrm{~h}$. Inoculation was realized after 20 days of plants acclimatization from nursery to green house. Four lemon rootstocks of 18-month-old were studied: Sour Orange, Volkameriana, Citrange Troyer and Flaying Dragon. Inoculation of leaves was carried out according to the technique of [8]. For each leaf inoculation experiment, five seedlings of each rootstock were used and four apical leaves in good state were chosen to be inoculated in four different sites of infection for the rootstocks Sour Orange and Volkameriana. But for the rootstocks Citrange Troyer and Flaying Dragon, the leaf inoculation was done only in three different sites as they have only three small blades as showed in the photos (Figure 1). In order to evaluate Mal Secco symptom's appearance and disease intensity an empirical scale was used. It was slightly modified and adopted by [11] which includes 4 degrees of disease intensity:

' 0 ': no sign of infection.

' 1 ': chlorotic halo around the inoculation point.

' 2 ': chlorosis of the vein close to the inoculation point.

' 3 ' vein chlorosis extending as far as the leaf edge.

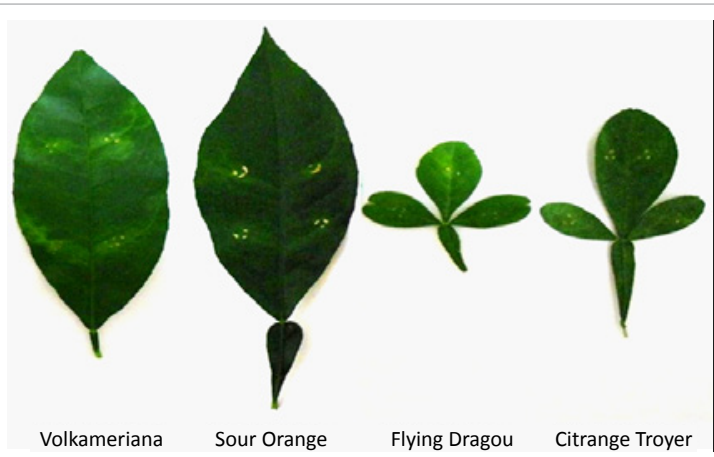

Figure 1: Leaves showing different intensity of symptoms according to their susceptibility to Mal Secco, 30 days post inoculation.
Positive Inoculation Percentage

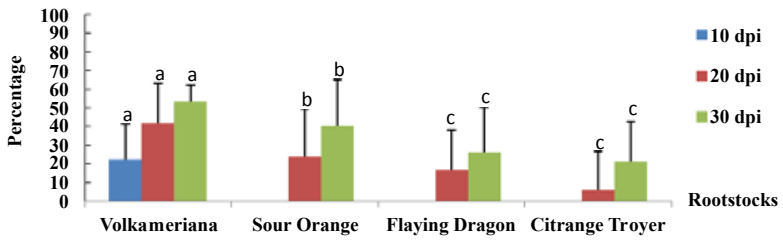

Figure 2: Positive Inoculation Percentage 10, 20 and 30 days post inoculation of leaf.

' 4 ': generalized chlorosis and/or browning of the veins close to the inoculation point.

\section{Statistical treatment of data}

Data of all the above measurements, obtained from sets of five plants per leaf inoculation test for each rootstock, were subjected to a factorial ANOVA/MANOVA analysis and means were separated by LSD test: Least Significant Difference test and divided into homogenous groups. Statistical analyses were made for each rootstock and each ten days post inoculation (dpi).

\section{Results and Discussion}

\section{Symptoms appearance}

Figure 1 is showing different mal secco symptoms in lemon leaves of the four rootstocks infected by Phoma tracheiphila after 30 days post inoculation (dpi). For Volkameriana there is a vein chlorosis extending as far as the leaf edge which matches to a high level the degree number ' 3 ' of leaves scale infection. However for Sour Orange, mal secco symptom is appeared by a chlorosis of the vein close to the inoculation point that suits to a medium level the degree number ' 2 ' of leaves scale infection. But there is only a chlorotic halo around the inoculation point appeared in the leaves of the two rootstocks Flying Dragon and Citrange Troyer. This symptom corresponds to a low level the degree number ' 1 ' of leaves scale infection. Through all these different mal secco symptoms, appeared after 30 days post inoculation (dpi), which are important indicators of diverse behaviors expressed under effect of artificial inoculation in leaves, the classification of these four lemon rootstocks has become possible according to resistance degree to the disease. Consequently, on the basis of the behaviors observed on the four Italian lemon rootstocks towards mal secco leaf infection with the Tunisian fungus Phoma tracheiphila causal agent of the disease, it has become possible to categorize these rootstocks used in inoculation. Thus Volkameriana is sensitive, Sour Orange is tolerant but Flying Dragon and Citrange Troyer are resistant to mal secco. Comparing these results with those obtained in previous trials carried out with other rootstocks, a differential susceptibility was observed in the behaviour of the tested citrus species towards infections when mature leaves were inoculated. In particular Sweet Orange was the least susceptible to Mal Secco, while Femminello lemon was the most susceptible. Monachello lemon and Sour Orange occupied an intermediate position [8]. These results concerning the rootstock Sour Orange are in a concordance with our results obtained through symptoms appeared in infected leaves after 30 days post inoculation (dpi).

\section{Positive inoculation percentage}

The results showing positive inoculation percentage are reported in figure 2. After leaf inoculation experiments different behaviors 
Average Disease Intensity

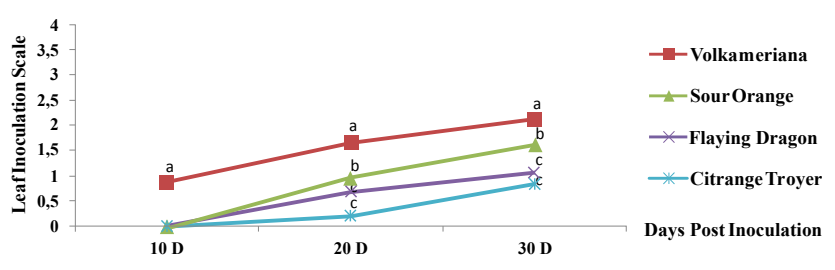

Figure 3: Average Disease Intensity 10, 20 and 30 days post inoculation of leaf.

have been shown in the four Italian lemon rootstocks. The graphics showed significant differences in the response of the four tested rootstocks face to Mal Secco infection. Ten days post inoculation, the positive inoculation was observed only on the rootstock Volkameriana and the percentage reached $21.87 \%$ with clear statistically significant difference. Nevertheless for the three other rootstocks the inoculation was expressed only after 20 days post inoculation. Hence the positive inoculation percentage for Sour Orange attained 23.75\%. But for Flying Dragon and Citrange Troyer it was lower and reached respectively $16.66 \%$ and $5.40 \%$ without any significant differences were observed between these two rootstocks. The following of inoculation after 30 days and determination of positive inoculation percentage, which attain from the highest to the lightest $53.12 \%, 40.31 \%, 26.04 \%$, and 20.94\% corresponding to the rootstocks Volkameriana, Sour Orange, Flying Dragon and Citrange Troyer, were useful for distinguishing the behaviour of the different rootstocks. A remarkable thing to mention is that these positive inoculation percentages are in a total agreement with the previous results showing different symptoms of the disease in the inoculated leaves. That is why taking into account both the clearness of the response and the accord with the behaviour of the different rootstocks it is possible to announce that there is one susceptible rootstock to mal secco disease Volkameriana, one tolerant rootstock Sour Orange and two resistant rootstocks Flying Dragon and Citrange Troyer. Comparing these results with those obtained in previous experiments done with other rootstocks, the results of leaf inoculation show that all tested rootstocks induced a lower susceptibility of the Lemon Scion than Sour Orange. On the whole, the trials reported here as well as the previous ones, all carried out in controlled environment and field observations, indicate that Citrange Yuma and Citrumelo Sacaton are the most susceptible rootstocks, all of which showed a clearly lower or intermediate susceptibility, seem to deserve further field investigations. However, it is worth of mention that these latter rootstocks showed a resistant behaviour rather close to that of the Siamelo and, more importantly, generally greater to that of the Sour Orange. It is of interest also that the susceptibility of the Lemon Scion changes, albeit slightly, according to the susceptibility of the corresponding rootstocks [12].

\section{Average disease intensity}

The results showing average disease intensity are reported in figure 3. According to the empirical scale of leaf infection comprising five degrees from ' 0 ' to ' 4 ', after ten days post inoculation (dpi), the infection reached 0.87 in Volkameriana, with a noticeable significant difference, which is about the degree number ' 1 ' of the scale corresponding to appearance of a chlorotic halo around inoculation point. Nevertheless no sign of infection was observed that is why the degree in the inoculation scale was null in the other rootstocks until the $20^{\text {th }}$ day post inoculation, when infection attains 0.95 in Sour Orange which also corresponds to the degree number ' 1 ' and no significant difference was observed. However the infection was less important in Flying Dragon and Citrange Troyer than in the other rootstocks and reached respectively 0.68 and 0.21 without any significant difference. On the other hand the infection degree increases and attains after 20 days post inoculation (dpi) 1.66 for Volkameriana which is about the degree number ' 2 ' of the scale corresponding to appearance of a chlorosis of the vein close to the inoculation point with a noticeable significant difference. Arriving to the $30^{\text {th }}$ day post inoculation, the results showed a rising of the average disease intensity in the four rootstocks and the infection reached 2.12 for Volkameriana with a noticeable significant difference which corresponds to the degree number 3 indicating the appearance of a vein chlorosis extending as far as the leaf edge. The average disease intensity attains 1.61 for Sour Orange without any significant difference. This average corresponds to the degree number ' 2 ' of the infection scale. But the lowest disease intensity was observed in Flying Dragon and Citrange Troyer with averages respectively 1.08 and 0.83 corresponding to the degree number ' 1 ' in the infection scale and there was no significant difference between these two rootstocks. As during the assessments following inoculation in all the lemon rootstocks, no average disease intensity arrived to the degree number ' 4 ' that is why no generalized chlorosis and/or browning of the veins close to the inoculation point was observed in the leaves. Therefore symptoms disease appearance showed in the photos of the infected leaves and average disease intensity represented by the different degrees in infection empirical scale are perfectly in a concordance for the four Italian lemon rootstocks used in artificial leaf inoculation. Seeing that all results showed the same behaviors for each rootstock either mal secco symptoms appearance or positive inoculation percentage and average disease intensity and associating analyses of different responses of all rootstocks infected artificially by Tunisian fungus Phoma tracheiphila, it is possible to determine and to classify these four rootstocks according to their susceptibility to mal secco disease.

The responses of these Italian lemon rootstocks to mal secco leaf infection in controlled environment with Tunisian fungus Phoma tracheiphila were investigated experimentally and the behaviors analyzed on the basis of empirical scale and most important mal secco symptoms. The tested lemon rootstocks infected artificially in controlled environment showed differential behaviors towards leaf infection, conduct to classify them according to degree of resistance and susceptibility to mal secco ranging from the high degree of resistance of Citrange Troyer to the intense susceptibility of Volkameriana. Also analyses of these different behaviors let consider Volkameriana susceptible, Sour Orange tolerant, Flying Dragon and Citrange Troyer resistant to Mal Secco.

The results were considered interesting when they permitted to well choose resistant lemon rootstocks Flying Dragon and Citrange Troyer which showed resistant behaviors to mal secco and reached almost the same degree in the leaf empirical scale. These results seem on the total quite satisfactory and thus may be considered a useful technical means to be used in the improvement for resistance of lemons to mal secco. For practical screening purposes and choosing the less susceptible rootstock it seems advisable to perform leaf inoculation, though allowing a safe assessment, do not kill the seedling, which is recoverable even when very susceptible. In order to save lemons and have a better reading of the results, screening operations must be stopped, and the infected leaves cut away, as soon as the symptoms on Volkameriana which is the most susceptible rootstock to the disease and have reached degree 4 and consequently showed generalized chlorosis and/or browning of the veins close to the inoculation point. 
Citation: Ziadi S, Chebil S, Ligorio A, Ippolito A, Mliki A (2012) Behavior of Italian Lemon Rootstocks towards Mal Secco Leaf Infection with Tunisian Fungus Phoma tracheiphila in Controlled Environment. J Plant Pathol Microb 3:150. doi:10.4172/2157-7471.1000150

\section{References}

1. Nigro F, Ippolito A, Salerno MG (2011) Mal secco disease of citrus: a journey through a century of research. J Plant Pathol 93: 523-560.

2. Crossa-Raynaud P (1960) Mal Secco. Extract vineyards, gardens and orchards Tunisia, 1-7.

3. CABI/EPPO (1989) Data Sheets on Quarantine Pests. EU contract 90/399003.

4. Gulsen O, Uzun A, Pala H, Canihos E, Kafa G (2007) Development of seedless and 'mal secco' tolerant mutant lemons through budwood irradiation. Sci Hortic 112: $184-190$.

5. Perrotta G, Graniti A (1988) Phoma tracheiphila (Petri) Kanchaveli \& Ghikashvili. European Handbook of the Plant Diseases 396-398, Ed. by IM Smith, J Duarez, RA Lelliott, DH Phillips, and SA Archer, eds. Blackwell Scientific Publications, Oxford.

6. Licciardello G, Grasso FM, Bella P, Cirvilleri G, Grimaldi V, et al. (2006) Identification and detection of Phoma tracheiphila, causal agent of citrus mal secco disease, by Real-Time Polymerase Chain Reaction. Plant Dis 90: 15231530.
7. Cutuli G, Laviola C, Perrotta G, Salerno M, Spina P (1984) Mal secco of citrus. International Seminar AGRIMED, Capo d'Orlando, Messina, Italy, 131.

8. Luisi N, De Cicco V, Cutuli G, Salerno M (1978) Factors in early testing for citrus mal secco resistance. Proc Int Soc Citriculture.

9. Traversa E, Ippolito A, Salerno M (1991) Indagini Epidemiological sul degl agrumi mal secco (Phoma tracheiphila). Fattori che influenzano it passaggio pathogen dale del foglie have rami. Phytopathologia Mediterranea 30: 59-63.

10. Salerno M, Catara A (1967) Ricerche sul mal secco degli agrumi (Deuterophoma tracheiphila Petri). VI. Indagini sulla riproduzione sperimentale della malattia. Riv Patol veg, Pavia (ser IV) 3: 89-97.

11. Loprieno N, Bugiani A (1958) Conservazione della forma del picnidica Deuterophoma tracheiphila in Petri coltura e della tecnica di innovazione infezione su di Arancio amaro piantine. Phytopath Z 32: 341-351.

12. Ippolito A, De Cicco V, Lima G (1990) Behaviour of some grafted lemon rootstocks towards Mal secco infections in controled environment. Proc XXIII Int Hort Congress, Firenze, Italia, 512. 